\title{
HEGEL Y EL DESTINO DE LA NOCIÓN MODERNA DE REPRESENTACIÓN
}

\section{HEGEL AND THE DESTINY OF THE MODERN NOTION OF REPRESENTATION}

\author{
José MARÍa SÁNCHEZ de LEÓN* \\ Ruprecht-Karls-Universität Heidelberg
}

RESUMEN: El artículo investiga el modo en que el tratamiento hegeliano de la noción moderna de representación concluye el proceso histórico que se inicia con el surgimiento de la misma. Partiendo de la relación entre las voces latinas species y repraesentatio se examina en primer lugar la evolución del concepto de representación a través de la edad moderna hasta llegar a Kant, el cual sienta las bases del tratamiento hegeliano. Se analiza a continuación la conceptualización hegeliana de la representación, la cual pone al descubierto su ambigüedad fundamental y la posibilidad de su superación por medio de la noción de signo.

PALABRAS ClAVE: Representación, especies, signo, realización, intuición, pasivi$\mathrm{dad} /$ actividad, exterioridad/interioridad, pensamiento, ámbito.

ABSTRACT: This paper investigates how Hegel's treatment of the modern notion of representation concludes the historical process that begins with its appearance. Beginning with the relationship between the Latin terms species and repraesentatio, the evolution of the concept of representation throughout modern times until Kant, who sets the groundwork for the Hegelian approach, is examined. After that, the Hegelian conceptualization of representation, which uncovers its latent ambiguity and the possibility of its sublation by means of the concept of sign, is also analyzed.

KEYWORDS: Representation, species, sign, realization, intuition, passivity/activity, exteriority/interiority, thought, domain.

* Dirección postal: José M. Sánchez de León Serrano. Dantestra e 22, 69115 Heidelberg. Email: oxintes@hotmail.com. 


\section{Consideraciones previas}

Con tal de evitar los posibles malentendidos a los que puede dar lugar el título de este artículo y a modo de aclaración preliminar acerca de lo que expondremos a continuación, tomaremos en consideración un pasaje de Heidegger extraído de su última lección de Marburgo del año 1928, dedicada al pensamiento de Leibniz: «Re-presentar no debe tomarse aquí en el sentido de una facultad particular del alma, sino en sentido ontológico estructural. La mónada no es por tanto en su esencia metafísica alma, sino lo contrario: el alma es una posible modificación de la mónada». ${ }^{1}$ De cara a las reflexiones que siguen no es necesario que elaboremos una interpretación detallada del pasaje citado ni que aclaremos el contexto del que está extraído, sino tan sólo que observemos una significativa conexión contenida en él. En el pasaje, en el que se trata del «representar» como rasgo esencial de la mónada leibniziana, se nos advierte en contra de toda interpretación, por así decirlo, "psíquica» del mismo. En lugar de ello hay que atribuirle al término una significación ontológico-estructural, en virtud de la cual lo que se entiende comúnmente por «alma», lejos de constituir esencialmente a la mónada, no es en realidad más que una modificación posible, es decir un modo de ser entre otros, de la misma. Entender el representar propio de la mónada como una facultad del alma equivaldría pues a confundir lo esencial con lo accidental, los atributos con los modos. El texto establece por tanto, a propósito de la noción de representación, la diferencia entre el plano de lo «estructural» (dejamos aquí de lado el epíteto «ontológico») y el de lo fáctico, empíricamente constatable. Es justamente en esta última acepción como no hay que tomar el término representar si se quiere captar su relevancia filosófica en Leibniz. Si ello no vale para Leibniz tampoco vale para el contexto más amplio en el que está englobado su pensamiento, y dentro del cual el término repraesentatio juega un papel central, a saber el período histórico conocido como «edad moderna». Observemos que el texto citado habla del alma como una modificación posible de la mónada, lo cual significa que son concebibles otras realizaciones concretas de la misma, o lo que es lo mismo: que respecto al re-presentar del que habla Leibniz, concebido estructuralmente, la interpretación "psíquica» es algo contingente. Esto ya nos proporciona algunas indicaciones importantes respecto a nuestra tarea, anunciada en el título. Entender la noción moderna

\footnotetext{
${ }^{1}$ M. Heidegger, GA Bd. 9, 386: «Vor-stellen ist hier nicht als ein besonderes Seelenvermögen zu nehmen, sondern ontologisch struktural. Daher ist die Monade in ihrem metaphysichen Wesen nicht Seele, sondern umgekehrt: Seele ist eine mögliche Modifikation von Monade».
} 
de representación implica remontarse desde sus posibles modificaciones o realizaciones contingentes a su significación estructural, la cual, precisamente por oponerse a lo fáctico o empíricamente constatable, no constituye para nosotros lo dado, el positum ya existente del que parte nuestra investigación, sino justamente aquello a construir ${ }^{2}$. Por eso hay que guardarse de atribuir de entrada al término toda significación psíquica o pneumatológica, la cual constituye lo dado, lo primero que se ofrece a la vista en los miles de enunciados y discursos concretos en los que aparece el término «representación».

El empleo del término «destino» en el título requiere también algunas aclaraciones. Si la noción moderna de representación, tal como acabamos de establecer, debe tomarse en su significación estructural, entonces hablar de algo así como un destino de la misma implica asumir que entre los caracteres esenciales (estructurales) de dicha noción está inscrito el que en su acontecer histórico concreto ella deba mostrarse de un modo determinado y no de otro. Que tal destino no pueda constatarse de otro modo que retrospectivamente o post festum es algo que no cambia nada en el asunto. En todo caso, el que el destino de la noción moderna de representación se presente en el título de este artículo asociado al nombre de Hegel indica que de ningún modo se van a tratar en él las opiniones o ocurrencias de un autor determinado respecto un asunto escogido más o menos al azar. En realidad, la advertencia recién hecha contra una lectura "psíquica» del término «representación» excluye ya una semejante comprensión del título. Lo que por consiguiente bajo el nombre de Hegel sucede con respecto a la noción de representación, y que a continuación vamos a tratar de exponer, no es algo que advenga a la misma de un modo puramente azaroso o externo, sino más bien algo que debe atribuirse a la noción misma y al acontecer que le es propio.

\section{De la species a la repraesentatio}

Según lo antedicho, no es el objeto de nuestra investigación consignar meramente las vicisitudes, según los autores y las épocas, del término «representación» a lo largo del período que le es propio, sino más bien observar su despliegue concreto basándonos en lo que más arriba hemos llamado la comprensión «estruc-

\footnotetext{
${ }^{2}$ Les notions philosophiques. Dictionnaire. Entrada «Structuralisme (ling.)».
} 
tural» del término. Hecha esta aclaración, empecemos señalando que la voz repraesentatio presenta en latín dos significaciones claramente diferenciadas. En primer lugar el término significa un pago, una prestación, un servicio, de carácter inmediato o instantáneo. En segundo lugar, repraesentatio puede significar tanto cierta acción como el efecto de la misma. La acción en cuestión puede describirse de modo muy general como mostrar, presentar a la vista, exhibir, manifestar, pero con la particularidad de que ese mostrar, exhibir, etc. hace referencia a algo que está ausente o que ya no está. El efecto de esa acción, es decir, lo mostrado, exhibido, manifestado, etc. también puede llamarse repraesentatio, y en ese caso la palabra pasa a designar el tipo de presencia de aquello que está ausente o que ya no está, como por ejemplo cuando hablamos de la imagen de un objeto como la «representación» del mismo, o como cuando decimos que el retrato de una persona constituye la «representación» de esa persona. De esa significación fundamental de hacer presente lo ausente se derivan el resto de acepciones, que no son más que concreciones de esa significación fundamental: repraesentatio como imagen mental, como reminiscencia de un suceso pretérito, como grupo de personas que actúa en nombre o en sustitución de una entidad, colectividad o corporación, como actuación teatral, como reproducción pictórica, como escenificación o evocación de hechos que ya han acaecido, etc. El denominador común de todas estas acepciones es que se trata siempre de un hacer presente de algún modo ${ }^{3}$ lo ausente. Importa recalcar el «de algún modo»: no se trata de convertir, transformar lo ausente en presente - como en el caso de revivir o resucitar-, sino de hacer que aquello que está ausente se haga presente sin que abandone su ausencia fundamental, es decir, de un modo que no contradiga su ausencia.

Para hacer más comprensible lo que estamos diciendo dirigiremos ahora nuestra atención a otra voz latina, que por su significación presenta un gran parentesco con repraesentatio, a saber el substantivo femenino species. Como repraesentatio, species designa también de entrada una presencia, algo que se muestra, se exhibe, se manifiesta, se presenta a la vista. Más concretamente, species significa el aspecto externo de algo, el brillo que ese algo desprende, el modo

${ }^{3}$ R. Goclenius, Lexicon philosophicum, quo tantam clave philosophiae fores aperiuntur (1613), artículo «Repraesento»: «absens modo quodam praesens facere». J. Micraelius, Lexicon philosophicum terminorum philosophis usitatorum (1653), artículo «Repraesentare»: «absens quodammodo facere praesens». 
en que se revela o muestra al exterior. De ahí se deriva el adjetivo speciosus, que significa atractivo, bello, espléndido, mas siempre con la connotación de «externalidad", de "hacia afuera» (no se emplea speciosus para referirse a cualidades internas) ${ }^{4}$. Tanto en el caso de repraesentatio como en el de species estamos pues ante la manifestación, el mostrarse, el ofrecerse a la mirada de algo. La diferencia reside en que — por decirlo de un modo algo vago, pero que se irá concretando a lo largo de nuestra investigación-, mientras que «tras» ese aparecer que constituye la species hay "algo", a saber, aquello de lo que ella es la forma externa o el brillo, la repraesentatio remite a algo que por definición está ausente. Como ejemplo clarificador de esta distinción puede ser útil mencionar el empleo de estos términos en el contexto teológico, en el que se habla de species en referencia a la transfiguración de Cristo, a apariciones de tipo sobrenatural, etc., mientras que repraesentatio se emplea en relación con la evocación de ciertos sucesos en el marco de la celebración eucarística. Basándonos en estos ejemplos podemos concluir que la species, a diferencia de la repraesentatio, es expresión de algo o remite a algo, en tanto que «surge» de ese algo o tiene su «origen» en él. Por el contrario, entre la repraesentatio y aquello a lo que ella remite no hay ninguna comunidad de tipo «natural», pertenecen, por decirlo así, a ámbitos del ser diversos ${ }^{5}$. No hay propiamente nada en la repraesentatio que nos permita pasar a aquello que ella representa o significa, salvo por medio de un vínculo puramente convencional, es decir, advenido, no constitutivo de los términos de la relación en cuanto tal ${ }^{6}$. En eso consiste precisamente la ausencia fundamental que está en el fondo de la noción de repraesentatio: puesto que entre la representación y aquello que ella representa no hay comunidad óntica de ningún tipo, aquélla sólo puede hacer a éste presente en la medida en que lo suplanta, se pone en su lugar, es decir, en la medida en que lo representado como tal no está o está ausente.

El sentido de estas digresiones en torno a las diferencias entre species y repraesentatio no es simplemente acotar el significado de repraesentatio por medio de un contraste u oposición. La relación entre ambos términos no se agota ahí. La operatividad de la voz repraesentatio, como hemos visto, consiste en expresar un

\footnotetext{
${ }^{4}$ Oxford Latin Dictionary, entrada "speciosus».

${ }^{5}$ E. Cassirer, Substanzbegriff und Funktionsbegriff, 373.

${ }^{6}$ E. Cassirer, íbid., 374.
} 
«hacer de algún modo presente lo ausente». Eso que en la repraesentatio figura como ausente, es precisamente lo que está presente en la species, entendido como aquello en lo que ésta tiene su origen o de lo que surge; aquello a lo que remite de un modo indirecto la repraesentatio es lo que la species presenta de modo inmediato $^{7}$. Si la repraesentatio indica pues la carencia de lo que está positivamente presente en la species, entonces aquélla debe ser considerada como "posterior»o «derivada» respecto a ésta, es decir como resultante de una supresión operada sobre la misma. Y así lo certifica la secuencia histórica de los conceptos, considerada desde el punto de vista de su operatividad filosófica: lo que antes se llamaba species pasa a partir de cierto momento a ser llamado repraesentatio. Con ello no se está diciendo que el uso de un término excluya el del otro; los textos nos muestran precisamente que ambos vocablos conviven durante largo tiempo en la literatura filosófica. Hay casos en los que incluso se llega a caracterizar al uno por medio del otro: la repraesentatio entendida como una forma o species, y la species como unida por un vínculo de representación con aquello de lo que ella es la apariencia externa. Aquí es preciso recordar que no es nuestro objeto consignar todo el sinnúmero de variaciones y vicisitudes ligadas a estas dos nociones. No obstante, hay que enlazar las reflexiones que acabamos de hacer con algunas precisiones historiográficas.

Según cierta historiografía al uso, habría que distinguir de entrada dos presuntas acepciones filosóficas del término species, una «ontológica» — que coincidiría más o menos con lo dicho hasta ahora de la species como forma externa de algo-, y otra que cabría calificar de «lógica». En realidad tal distinción, aplicada al término en su origen, carece de validez; se trata más bien de algo posterior, resultado precisamente — como vamos a mostrar a continuación - del viraje o cambio de paradigma que intentamos explicar aquí. Species es, de entrada, el término

${ }^{7}$ J.-L. Marion, Sur la théologie blanche de Descartes, 243: "Car la species doit moins s'entendre comme une «image», qui se substitue à la chose, que comme l'aspect que prend la chose même, pour s'offrir à voir par l'esprit. Sous les espèces de la species, la chose même se fait intentionelle; mieux, elle fait part de son intention de se faire (re-)connaître par l'esprit; la species ne reproduit pas tant une chose absente, qui s'y déléguerait, qu'elle n'offre le visage par lequel la chose se produit sur la scène d'une connaissance possible. La species met donc en scène la chose même, car elle ne consiste qu'en l'entrée en scène de la chose, loin de la reproduire d'una reproduction d'autant plus distincte de l'original qu' elle lui ressemblerait plus fidèlement et s'y substituerait.» 
que emplea Cicerón para traducir la noción platónica de $e^{i d o s^{8}}$. El pensamiento romano conocerá otras traducciones alternativas del mismo término- algunas propuestas por el mismo Cicerón-, como forma o exemplar. Sin embargo, la noción de species presenta una peculiaridad, de la que justamente derivará su relevancia histórica posterior. Como ya hemos dicho, la voz latina species significa en su acepción prefilosófica - algo así como el brillo, la forma externa, visible de algo, lo cual la hace muy apta como traducción del término platónico, filosóficamente fijado, de eidos. Sin embargo, species también puede, en virtud de su riqueza semántica, designar aquello que en la recepción helenística de la doctrina platónica se considera en cierto modo como lo contrapuesto al eidos (concebido como «modelo» o «arquetipo»), esto es la copia, el fantasma, el simulacro, en griego eidôlon. Esta capacidad de acoger en sí dos significaciones contrapuestas es lo que posibilitará, varios siglos más tarde, que species se convierta en el concepto central en torno al cual girarán los debates gnoseológicos de la escolástica de los siglos XIII y XIV. A modo de caracterización muy somera de estos debates, de los que ahora no nos podemos ocupar en detalle, digamos simplemente que en ellos se trata de hacer inteligible el encuentro o el ajuste entre la res o la realidad extra animam y el intelecto (concebido ya como separado de la res), ajuste en el que — según los presupuestos de la escolástica- debe consistir precisamente el conocimiento. El término species, en virtud de la mencionada capacidad de acoger dos significaciones contrapuestas, permite, a modo de medium entre res y anima y con adición del concepto de intentio, hacer comprensible dicho ajuste. La discusión en torno a las species intentionales se prolongará hasta la escolástica tardía (Cayetano, Juan de Sto. Tomás, Suárez), pero la noción de species es ya en el siglo XIV y dentro de la escolástica misma (Ockham) objeto de demoledores ataques que ponen en duda su pertinencia como concepto9 ${ }^{9}$. Fuera del ámbito de la escolástica, el término species deja progresivamente de emplearse en el sentido mencionado y su uso se restringe al campo de la lógica y la biología. En tiempos de Kant species ya sólo se entiende en estas dos acepciones. El abandono del término va acompañado de la creciente acuñación de la voz repraesentatio. Veámoslo con más detalle.

Como ya hemos indicado más arriba, entre la species y aquello de lo que ella constituye el aspecto o la forma externa hay similitud, comunidad óntica. No

\footnotetext{
${ }^{8}$ Vocabulaire europée des philosophies. Entrada «Species».

${ }^{9}$ D. Perler, Descartes, critique de la théorie médiévale des species, 151-153.
} 
así en el caso de la repraesentatio, de la cual por definición no puede deducirse la existencia (ausente) de aquello que ella reproduce o presenta ${ }^{10}$. Que en la discusión filosófica en torno al ajuste entre la res y el intellectus desaparezca el término species como medium entre ambos significa ni más ni menos que la comunidad óntica que los vincula ha dejado ser considerada obvia. Al romperse todo vínculo óntico entre los términos de la relación, la operación de inteligir su correspondencia mediante nociones como «similitud» o «analogía» — pertinentes justamente en virtud de esa comunidad fundamental — pierde toda validez. La referencia del intellectus a la res extra animam sólo puede ser concebida entonces a partir de un «hacer presente» algo que como tal no está o está ausente, es decir, mediante una repraesentatio. La noción de repraesentatio se muestra así esencialmente ligada a lo que J.-L. Marion ha llamado — en referencia a la doctrina expuesta en las Regulae de Descartes y a la época que ellas inauguran- una «ontología por denegación»". Si la referencia a la cosa, a la res, tiene lugar mediante representación, entonces el abordaje de la cosa no puede llevarse a cabo por medio de rasgos o marcas procedentes de ella misma. La cosa deja de este modo de poseer en sí misma el fundamento de su conocimiento: no accedemos más a la cosa por aquello que ella desprende de sí o imprime en nosotros a modo de huella. La cosa no «habita» propiamente más en ella misma — lo que Marion llama «alienación de la cosa»—, sino en el otro término de la relación epistémica, en el cognoscente, aquél precisamente que se forma representaciones, reproducciones de la cosa sin vínculos ónticos con la misma ${ }^{12}$. De ahí no se sigue que la cosa se pierda inevitablemente y el cognoscente se quede, por así decirlo, solo con sus representaciones, sino que la cosa es reencontrada a otro nivel, no ya conforme a lo que ella en sí misma es, sino conforme al intelecto que la concibe o representa. Ese nuevo nivel es lo que se conoce como «objetividad», noción estrictamente moderna y no separable del entramado conceptual que estamos describiendo. La tarea que se impone entonces la edad moderna, entendida como «época de la representación», es la de dilucidar en qué consiste propiamente la referencia válida a la cosa («objetividad») desde el presupuesto de su no-presencia inmediata.

\footnotetext{
${ }^{10}$ E. Cassirer, ibid., 374.

${ }^{11}$ J.-L. Marion, Sur l'ontologie grise de Descartes, 186.

12 J.-L. Marion, íbid., 186-187.
} 
Este último resultado de nuestra reflexión requiere aún algunas precisiones más. Ha quedado establecido que la noción de representación surge de la supresión del vínculo óntico de la species con aquello de lo que ella constituye la forma externa. La consecuencia más inmediata de esa supresión es la imposibilidad de un acceso inmediato a la cosa: el modo de presencia de la cosa, esto es, por representación, no permite asumir sin más la presencia efectiva de la misma. La existencia de la cosa se vuelve de este modo, en virtud de su exterioridad constitutiva respecto a la representación, inevitablemente dudosa; la referencia válida a la misma en el discurso (objetividad) requiere entonces una justificación específica. Dicha justificación sólo puede llevarse a cabo partiendo de aquella instancia cuya existencia o presencia efectiva no se ha visto afectada por la supresión del vínculo óntico entre la species y la res. ¿Qué existencia, qué cosa efectivamente dada puede hacer excepción a la pérdida (general) de la cosa que conlleva la noción de representación? El único «algo», la única cosa existente que puede exceptuarse a esa pérdida general es la representación misma. No hablamos de ninguna representación en particular, sino del hecho de la «representatividad» en cuanto tal. La representatividad, o dicho de otra manera, el ámbito que integra todas las representaciones, es lo que más arriba hemos llamado el cognoscente, y que a lo largo de la edad moderna recibe distintas denominaciones: cosa pensante, yo, alma, sujeto, unidad de apercepción, etc. El problema propiamente moderno i. e. la referencia válida a la cosa- sólo admite solución tomando como punto de partida "lo único que hay», esto es la instancia de la representatividad. Lo cual no significa que el problema se resuelva exclusivamente por medio de esa instancia. En efecto, resulta difícil ver cómo, partiendo exclusivamente de la representación y su constitutiva desvinculación respecto a la res, puede accederse a un conocimiento válido de la cosa, i. e. al plano de la objetividad ${ }^{13}$. La estructura misma de la representación, tal como la hemos descrito, hace de antemano imposible un paso semejante. Salvo que entre las innumerables representaciones - $\mathrm{O}$ modos de presencia de la cosa (ausente) en el ámbito de la representatividadhallemos una determinada que no se adecue a la estructura de la representación. En dicha representación debería entonces poder hallarse lo que falta constituti-

${ }^{13}$ Empleando términos de Guéroult, podemos expresar lo mismo diciendo que el ego concebido como fundamento de objetividad no constituye ipso facto el fundamento del valor objetivo de la representación (el cual es Dios). Véase M. Guéroult, Descartes selon l'ordre des raisons, 1er. Vol., 136-137. 
vamente en las demás, esto es el vínculo con una realidad efectivamente dada. Dicha representación lleva por nombre «Dios», y la operación intelectual de encontrar su configuración adecuada y extraer (únicamente) de ella la conclusión de existencia de su repraesentatum es lo que se conoce como "prueba ontológica», otro motivo típicamente moderno no transferible a otros contextos. De este modo, por medio de aquella representación que es «más» que una mera representación, se opera el paso a la cosa inicialmente ausente en la estructura de la representación ${ }^{14}$.

\section{Kant y la asunción consecuente de la noción de representación; planteamiento de la problemática en la que se inserta el tratamiento hegeliano.}

Quedan por hacer algunas aclaraciones más antes de pasar a Hegel y su papel en todo este asunto. La noción moderna de objetividad ha sido más arriba definida como la referencia válida a la cosa desde el presupuesto de su no-presencia inmediata. La prueba ontológica adquiere entonces sentido cuando dicha referencia se concibe como un remitir de la representación a aquello de lo que ella está constitutivamente desligada, esto es, a la res. La ausencia inicial de la cosa así alcanzada es entendida como ausencia en el ámbito "particular» de la representatividad, esto es como mera exterioridad respecto a la misma, no como ausencia de la cosa lisa y llanamente. Pero la asunción radical y consecuente de la noción de representación, entendida como «lo que hay» ${ }^{15}$, trae consigo el que ésta no constituya un ámbito entre otros, y por tanto el que no sea concebible cosa alguna "fuera de ella». La referencia válida a la cosa u objetividad deja de este modo de ser entendida como congruencia entre res y repraesentatio, y pasa a ser conce-

\footnotetext{
${ }^{14}$ Lo descrito en este párrafo es claramente una exposición resumida y extremadamente simplificada del hilo argumentativo de las Meditationes de Descartes. Somos conscientes de que la posición cartesiana no puede hacerse extensiva a todos los autores de su época, pero lo que nos interesa de la misma es lo que tiene de inaugural respecto a las problemáticas que estamos tratando aquí. Respecto al último punto, en el que se trata de Dios como aquello que se sustrae a la estructura de la representación (y de este modo queda demostrada su existencia), la referencia más pertinente sería sin embargo N. Malebranche, De la recherche de la vérité, IV, cáp. XI, 459-469.

${ }^{15}$ Del mismo modo - es decir, como lo que hay- puede caracterizarse otro término central en la edad moderna, a saber, idea. Véase F. M. Marzoa, Pasión tranquila. Ensayo sobre la filosofía de Hume, 20.
} 
bida como congruencia de la representación consigo misma ${ }^{16}$. Hay referencia válida a la cosa, hay objetividad en sentido estricto, cuando las representaciones concuerdan entre sí y conforman estructuras, cuando presentan regularidad y determinación. La figura en que se encarna por primera vez esta asunción consecuente de la noción de representación es Leibniz, pero su teorización más detallada la hallamos en Kant. Cuando Kant se plantea explícitamente la tarea de explicar la representación, declara que ésta es inexplicable, pues para explicar la representación hay que servirse ya de representaciones ${ }^{17}$. En efecto, ¿cómo explicar «lo que hay» mediante elementos inclusos ya en «lo que hay»? Todo es primariamente representación, aunque dentro de ella quepa hacer ulteriores distinciones, taltes como concepto y sensación, entendimiento e intuición, etc. que propiamente no son más que «tipos» o «clases» de representación. Observemos algunas de las consecuencias de esta posición. La más notable tiene que ver con lo que más arriba, siguiendo a Marion, hemos llamado la «alienación de la cosa». La sustitución del concepto de species por el de repraesentatio comporta, dijimos, que la cosa deje de poseer en sí misma el fundamento de su conocimiento y que éste se desplace al otro polo de la relación epistémica. Lo que la cosa en sí misma sea, la constitución que ella presente con independencia de la instancia de la representatividad, se vuelve así un asunto del todo irrelevante. Ahora bien, si la referencia válida a la cosa se basa, como acabamos de establecer, en la concordancia de las representaciones entre sí, cabe entonces preguntarse: ¿qué aporta exactamente a las representaciones su concordancia? ¿Cuál es el principio de su ordenación? Concordancia entre sí de las representaciones no significa otra cosa que unidad de las mismas, y ésta sólo puede provenir de aquella instancia que las integra todas, esto es el cognoscente o sujeto. Se produce así un interesante giro en la cuestión de la referencia válida a la cosa que irá ganando importancia en nuestras próximas reflexiones. La referencia válida a la cosa u objetividad se acaba de mostrar como el resultado de un referir efectuado, por decirlo así, «dentro» del ámbito de la representatividad misma, y concebido como congruencia de las representaciones entre sí. Si la validez de ese referir proviene de aquella ins-

${ }^{16}$ W. Janke, Leibniz. Die Emmendation der Metaphysik, 112: «Die Wahrheit von Phänomenen ist dabei nicht zu ermitteln als Kongruenz von Vorstellung (intellectus) und Sache (res), sondern als Kongruenz des Vorgestellten an ihm selbst; seine "Wirklichkeit» bemißt sich an der ihm eigentümlichen und mit allen anderen zusammenstimmenden Regelhaftigkeit.»

${ }^{17}$ Kant, Logik, A 42: «Und diese (die Vorstellung) läßt sich durchaus nicht erklären. Denn man müßte, was Vorstellung sei, doch immer wiederum durch eine andere Vorstellung erklären.» 
tancia que integra todas las representaciones, esto el «representante», entonces el referir a la res propio de la representación está por así decirlo incluído en un acto de referencia mayor, dirigido precisamente al agente de la representación mismo, al sujeto ${ }^{18}$. La indefinibilidad, por tanto, que Kant atribuye a la noción de representación conlleva entonces que la referencia válida a la cosa deba fundarse en una «autorreferencia». La aportación hegeliana, como se va a mostrar más adelante, atañe precisamente a este último resultado.

Justo en este punto se hace visible una ambigüedad en la noción kantiana de representación cargada de consecuencias, de la cual va a arrancar precisamente el tratamiento hegeliano con toda su fecundidad. Según Kant la representación es, como acabamos de ver, inexplicable, o dicho de otra manera: ella es todo, de modo que toda distinción ulterior tiene lugar dentro de su ámbito. Mas, a pesar de dicha inexplicabilidad, la representación sigue conservando los rasgos propios que le hemos atribuído desde el principio, a saber, el ser esencialmente referencia a la res. En virtud de esa referencia a la res, la representación se distingue de o se opone a la recién indicada referencia al sujeto que hemos señalado como presuposición de la referencia válida al objeto (u objetividad). Simplifiquemos ahora un poco los términos y llamemos a lo que más arriba hemos denominado «cuestión de los tiempos modernos» - i. e. la pregunta por la referencia válida a la res desde el presupuesto de su no-presencia inmediata- la "cuestión del conocer». En su Lógica Kant afirma que nuestro conocer presenta una referencia doble, por un lado al objeto, por otro lado al sujeto. Según lo primero el conocimiento se refiere a la representación; de acuerdo con lo segundo él se refiere a la conciencia. La referencia al objeto acompañada de conciencia, o referencia al sujeto, es lo que hace posible que haya conocimiento ${ }^{19}$. De ahí que Kant un poco más adelante declare que la representación no es aún conocimiento, sino su presuposición, de lo que se deduce que efectivamente la representación presenta un opuesto, lo cual desmiente su recién establecida condición de «omnienglobante» ${ }^{20}$. Sin embargo, Kant insiste en hacer

${ }^{18}$ F. M. Marzoa, Hölderlin y la lógica hegeliana, 20.

${ }^{19}$ Kant, Logik, A 40, 41: «Alle unsre Erkenntnis hat eine zweifache Beziehung, eine Beziehung auf das Objekt, zweitens, eine Beziehung auf das Subjekt. In der ersten Rücksicht bezieht sie sich auf Vorstellung; in der letzteren aufs Bewußtsein, die allgemeine Bedingung alles Erkenntnisses überhaupt.(Eigentlich ist das Bewußtsein eine Vorstellung, daß eine andere Vorstellung in mir ist)».

${ }^{20}$ Kant, Logik, A 42: «Aber Vorstellung ist noch nicht Erkenntnis, sondern Erkenntnis setzt immer Vorstellung voraus.» 
de la referencia al sujeto también una representación, lo cual presentaría coherencia con la afirmación de que la representación no se deja explicar. Hay pues vacilación, ambigüedad en la posición kantiana: la representación es captada como siendo miembro de una oposición y al mismo tiempo como no teniendo opuesto, esto es, siendo «omnienglobante». Señalemos ya que no se trata de una mera incoherencia terminológica, sino de una tensión inherente al concepto mismo. Hemos dicho más arriba que la creciente acuñación del término «representación» indica un desplazamiento del fundamento del conocer hacia el polo opuesto a la res en la relación epistémica, esto es, el cognoscente. El reconocimiento de la inexplicabilidad de la representación, por otra parte, se ha mostrado como el resultado de la asunción consecuente de su concepto, de tal modo que el polo opuesto al sujeto, la res, ha dejado de constituir un «afuera» respecto al ámbito de la representatividad. De ahí se ha derivado la noción de autorreferencia como aquello que hace posible el conocer. Con todo, la autorreferencia se opone a la referencia a la res, y de ahí que Kant declare que la Vorstellung, entendida como referencia al objeto, no constituye aún conocimiento, pues para que lo haya debe haber referencia al sujeto, que no es res. De todo ello podemos concluir lo siguiente: aquello a lo que la noción de representación apunta —i. e. el desplazamiento del fundamento del conocer al otro polo de la relación epistémica, al sujeto — no alcanza, o mejor dicho: no puede alcanzar en ella, su cumplimiento. Para que dicho desplazamiento efectivamente se cumpliese la Vorstellung debería dejar de ser «omnienglobante», mas ser «omnienglobante» se ha mostrado justamente como la consecuencia de su asunción radical (y, por tanto, de aquello a lo que ella «tiende» o «apunta»).

¿Cómo se inserta en este contexto el planteamiento hegeliano? Dicho contexto es el que acabamos de establecer como aquél que está regido por la cuestión del conocer. El conocer, por otro lado, se muestra ya en Leibniz como basado en la referencia al yo o autorreferencia. Si, como señala Kant, el representar pasa a ser verdadero conocer cuando la referencia a la cosa va acompañada de referencia al sujeto, entonces el conocer puede ser descrito — de un modo que todavía se ha de concretar más- como una suerte de «apropiación». En estos términos se expresa justamente Hegel (en un pasaje en el que no se distingue apenas entre saber y conocer): conocer es poner lo ajeno como propio ${ }^{21}$. Apropiarse significa desposeer de autonomía lo ajeno e incorporarlo a lo «propio»; al

${ }^{21}$ Enzyklopädie der philosophischen Wissenschaften (edición de 1832) (en adelante Enz.), \$445. 
apropiarse lo ajeno se le quita por tanto lo que tiene de «limitador»o «negador» de nuestro yo. De este modo el conocer se muestra como un «afirmarse», un «realizarse»: el conocer es, en tanto que el hacer propio de la inteligencia, la realización efectiva de la misma ${ }^{22}$. Esto tiene importantes consecuencias con respecto a lo que hemos llamado la cuestión de los tiempos modernos, esto es, la pregunta por el conocer desde el presupuesto de la no-presencia inmediata de la res. Dicha pregunta, como sabemos, sólo adquiere sentido si se parte del presupuesto de que «lo que hay» es representación. Si lo que hay es representación, ¿cómo es posible eso que llamamos el conocer, esto es, un referir de modo válido a la cosa? Mas si la pregunta se formula de este modo, es decir, acerca de la posibilidad del conocer, se está asumiendo como igualmente posible que el conocer no se dé. Si el conocer es abordado como algo posible (entendiendo esto último como distinto de lo que «efectivamente se da»), entonces es igualmente posible su contrario, el no-conocer. Cabe pues pensar, desde el presupuesto de la representatividad, que el representar no se refiera a res alguna. Observemos que es el presupuesto de la representatividad el que nos obliga a plantear la pregunta en estos términos. De ahí se derivan otras muchas consecuencias, entre las cuales cabe destacar el discurso típicamente moderno acerca de las «facultades del alma». La comprensión del conocer como una facultad del alma entre otras conlleva que el alma pueda dejar de conocer y ejercerse en otra actividad, como, pongamos por caso, imaginar, recordar, etc. Si hay algo así como facultades del alma, si el alma puede ejercerse en actividades diversas, y el conocer es — de modo puramente contingente- «una más» entre ellas, entonces el conocer, como acabamos de decir respecto a la cuestión moderna, puede perfectamente no darse. Hay pues una correlación estricta entre la asunción de "facultades del alma» y el modo en que se formula la cuestión de los tiempos modernos ${ }^{23}$, y todo ello descansa, como hemos visto, sobre el presupuesto de la representatividad. Ahora bien, el conocer es — según la caracterización hegeliana— esencialmente «realización

${ }^{22}$ Enz. $\$ 445:$ «Der Begriff des Erkennens hat sich als die Intelligenz selbst, als die Gewißheit der Vernunft ergeben; die Wirklichkeit der Intelligenz ist nun das Erkennen selbst».

${ }^{23}$ Enz. $\$ 445:$ :Das Tun der Intelligenz als theoretischen Geistes ist Erkennen gennant worden, nicht in dem Sinne, daß unter aderem auch erkenne, außerdem aber auch anschaue, vorstelle, sich erinnere, einbilde usf; eine solche Stellung hängt zunächst mit dem soeben gerügten Isolierung der Geistestätigkeiten, aber ferner hängt damit auch die große Frage neuerer Zeit zusammen, ob wahrhaftes Erkennen, d. i. die Erkenntnis der Wahrheit möglich sei; so daß, wenn wir einsehen, sie sei nicht möglich, wir dies Bestreben aufzugeben haben.» 
efectiva», «afirmación», es decir, lo opuesto a una mera "posibilidad». No cabe hablar del conocer como algo que podría no darse, pues ello es contrario a su concepto, que es precisamente el de «afirmación». El conocer no es una actividad «entre otras» del alma, sino el hacer de la inteligencia, único por tanto, pues en virtud del mismo ella "se realiza», "se afirma». Mas dicha comprensión del conocer presupone también la noción de representatividad; el tratamiento de la misma nos ha llevado a él, a pesar de que el conocer basado en la representatividad se plantee como una posibilidad, y no como una «realización». Tenemos, por tanto, que la noción de representación obstaculiza el cumplimiento de aquello que ella misma posibilita o pone en marcha, de tal modo que ella puede ser caracterizada como una "apropiación inconclusa».

La vacilación terminológica que hemos detectado en Kant debe ser interpretada como índice de esta apropiación inconclusa. Como tal debe ser vista también la mencionada «inexplicabilidad» de la noción de representación. Esto nos permite ya entrever en qué va a consistir la tarea de Hegel. Puesto que la inexplicabilidad de la representación, i. e. la asunción de la misma como «omnienglobante», imposibilita el cumplimiento de aquello a lo que ella apunta, esto es la realización/afirmación del conocer, es preciso contraponerla a otro término en relación al cual ella figure como aquello a ser apropiado, y dicho término - puesto que aquello que «se afirma» es la inteligencia o el sujetono puede ser otro que el "pensamiento». Ahora bien, en la kantiana concepción de la representación el pensamiento figura como una de las dos clases de representación (repraesentatio per notas comunes), siendo la otra la intuición (repraesentatio singularis $)^{24}$. Si, como acabamos de señalar, la representación debe ser distinguida del pensamiento asumiendo el papel de aquello «a apropiar», entonces no hay más remedio que identificarla con la intuición, la cual funciona en Kant justamente como el punto de partida del conocer. Con lo cual estamos más o menos igual que al principio, pues seguimos en realidad dentro del esquema kantiano pero con nombres distinos. Consciente de dicha dificultad, Hegel introduce otra distinción, esta vez entre la intuición y la representación. De este modo, colocada a medio camino entre la intuición y el pensamiento, la representación asume explícitamente los rasgos de una apropiación inconclusa. Así es como hay que entender el pasaje siguiente: «La

\footnotetext{
${ }^{24}$ Kant, Logik A 139, 140.
} 
representación, en tanto que intuición interiorizada, es el término medio entre el inmediato encontrarse-determinado de la inteligencia y ella misma en su libertad, es decir, el pensamiento ${ }^{25}$. En este pasaje está condensada programáticamente la teorización hegeliana de la representación. A continuación vamos a desplegar los distintos aspectos contenidos en él.

\section{El conocer como realización y sus fases}

Podría parecer que con las distinciones recién hechas (representación distinta de intuición; representación distinta de pensamiento) recaemos en la antes mencionada asunción de "facultades del alma», en virtud de la cual el conocer, captado como «una más» entre un número contingente de actividades, bien podría no darse. Pero el sentido de las distinciones hechas - y eso es clave para la comprensión del pasaje que nos ocupa- es justamente el contrario, pues se trata de distinciones hechas con arreglo al conocer concebido como «realización»o «afirmación», respecto al cual, por tanto, no cabe pensar que alguno de sus elementos constituyentes «falte» $\mathrm{o}$ «no se dé», pues eso impediría precisamente la «realización» en la que el conocer esencialmente consiste ${ }^{26}$. Se trata más bien de lo que Hegel, empleando una terminología extraída de la física, llama «momentos», es decir de distinciones que, a pesar de su diversidad, convergen en un mismo resultado o se resuelven en lo mismo ${ }^{27}$. La comprensión del conocer como el hacer de la inteligencia, en virtud del cual ella se «realiza», nos obliga pues a establecer como único fin de las «facultades del alma» el concepto del conocer, por tanto a contemplarlas como «momentos» del mismo. Del mismo modo debe

\footnotetext{
${ }^{25}$ Enz. $\$ 451$ : «Die Vorstellung ist als die erinnerte Anschauung die Mitte zwischen dem unmittelbaren Bestimmt-sich-finden der Intelligenz und zwischen derselben in ihrer Freiheit, dem Denken.» La traducción que hemos ofrecido en nuestro texto es la Ramón Valls Plana, el cual traduce "erinnerte» como «interiorizada», mientras que en su sentido habitual significaría «recordada»; la opción de Valls Plana por la primera en lugar de la segunda nos parece plenamente justificada.

${ }^{26} E n z . \$ 445$ : «Es folgt daraus, daß es ungereimt ist, von der Intelligenz und doch zugleich von der Möglichkeit oder Willkür des Erkennens zu sprechen. Wahrhaft aber ist das Erkennen, eben insofern sie es verwirklicht, d. i. den Begriff desselben für sich setzt. Diese formelle Bestimmung hat ihren konkreten Sinn in demselben, worin das Erkennen ihn hat. Die Momente seiner realisierenden Tätigkeit sind Anschauen, Vorstellen, Erinner usf.; die Tätigkeiten haben keinen anderen immanenten Sinn; ihr Zweck ist allein der Begriff des Erkennens.»

27 Wissenschaft der Logik. Die Lehre vom Sein (1832), 95-96.
} 
entenderse el empleo de la expresión «término medio» (Mitte en alemán) aplicada a la representación en el pasaje citado. Bajo dicha expresión no hay que entender un mero estar entre dos cosas; el sentido meramente espacio-temporal de la expresión debe ser sustituído por otro, proveniente de la lógica en los tiempos de Hegel. Término medio alude desde esta perspectiva a uno de los tres términos del silogismo, aquél cuya función consiste en poner en relación el menor y el mayor posibilitando de este modo la inferencia deductiva. La representación oficia en este sentido de término medio entre la intuición y el pensamiento, por cuanto presenta rasgos característicos de ambos y de este modo los conecta. La inferencia deductiva en cuestión aquí es el conocer entendido como "realización", el cual no se daría efectivamente si no hubiese dicha conexión o encadenamiento, es decir, si sus momentos figurasen más bien como actividades desligadas entre sí (las cuales, por tanto, podrían «no darse»). Pero hay más. Como bien se sabe, el término medio está ausente en la conclusión del silogismo: la conexión efectiva de los términos a relacionar requiere que aquello que los conecta, el mediador entre ambos, desaparezca. En dicha desaparición del término medio consiste precisamente el más arriba mencionado cumplimiento efectivo de aquello a lo que apunta la noción de representación y que, como vimos, exige ir más allá de la misma.

El pasaje citado establece que el encadenamiento efectivo de los momentos del conocer (mediante el cual el mismo «se realiza») se produce por cuanto la representación — término medio entre el intuir y el pensar- es «intuición interiorizada». Que lo que distingue la representación de la intuición sea un mero epíteto indica que la diferencia entre ambas no es de "contenido». Intuición y representación tienen en común un mismo contenido, el cual en el caso de la representación se presenta bajo el modo de la «interioridad». Para entender en qué consiste exactamente la «interioridad» — sin caer en las lecturas «psíquicas» contra las que advertíamos al principio de nuestra exposición- es preciso que aclaremos el término en relación a su opuesto, la «exterioridad». «Exterioridad» es la manera en que se presentan los contenidos de la intuición en el ámbito específico de la intuición (no en el de la representación), es decir, los unos fuera de los otros, o dicho de otra manera, sin conexión necesaria entre sí. Cabe distinguir dos formas de exterioridad: la sucesividad (tiempo) y la coexistencia (espacio); tiempo y espacio son pues las formas bajo las cuales tiene lugar todo «uno-fuera-de-otro». Si la exterioridad es pues el modo en que se presentan los contenidos de la intuición, sin constituir dicho modo un contenido en cuanto 
tal, entonces la interioridad no tendrá de entrada otra significación que la presencia de los mismos contenidos, pero «aislados» o «extraídos» del contexto propio de la intuición, es decir, de la espacio-temporalidad. El aislamiento de un contenido de la intuición "fuera» del contexto de la espacio-temporalidad es lo que se conoce como recuerdo y constituye la forma más elemental de representación. Debe insistirse aquí de nuevo en contra de toda lectura "psíquica» del estado de cosas que estamos describiendo. La interioridad de la que se está hablando aquí no debe interpretarse en términos de una "psique» contrapuesta a un «mundo externo». Lo que hemos llamado exterioridad no tiene nada que ver con un «mundo externo» fuera de la «mente»; de hecho, en la exterioridad entendida como forma de la intuición está presente la inteligencia, por decirlo así, «toda entera» ${ }^{28}$. De acuerdo con la comprensión del conocer como «realización», la intuición constituye algo así como el "punto cero» de dicha realización; al respecto Hegel dice que en la intuición el espíritu «es para sí mismo de índole material (stoffartig) ${ }^{29}$. La referencia a la materialidad nos proporciona una indicación importante, pues la marca distintiva de la materialidad es la pasividad, y de ahí se sigue que con el paso de la intuición al recuerdo la inteligencia comienza a actuar, y de este modo a «afirmarse» o «realizarse»; la interioridad es por tanto sinónima de actividad. Recordemos lo que más arriba se dijo acerca de la apropiación: ella consiste en desposeer de autonomía lo ajeno e incorporarlo así a lo propio. El ámbito de lo propio, aquél en el que la inteligencia es activa, es precisamente la interioridad. El origen espacial del par exterioridad/interioridad no debe despistarnos aquí; interioridad debe ser leído como sinónimo de actividad, afirmación, realización efectiva, esto es, lo que hemos atribuído a la inteligencia como su hacer propio. Exterioridad, en cambio, no indica en este contexto otra cosa que la inteligencia en la fase previa a su realización, en su materialidad inicial. Pero hay algo en la referencia espacial que sí debe ser retenido, a saber: una interioridad no «limitada» por lo externo no sería interioridad alguna. El sentido pues de emplear términos como interioridad y exterioridad es el de indicar que la actividad de la inteligencia está en algún punto restringida o limitada. Por eso precisamente habla Hegel de la representación como «intuición interiorizada»; el epíteto «interior» adquiere sentido aplicado a la representación en tanto que indica «restricción», «límite», y lo esencial de

\footnotetext{
${ }^{28}$ Enz. $\$ \$ 446-447$.

${ }^{29}$ Enz. $\$ 446$.
} 
la representación que hemos señalado ya varias veces es el ser justamente una realización obstaculizada, restringida. De ahí se desprende que el cumplimiento efectivo de aquello a lo que apunta la noción de representación deberá conllevar la disolución de la distinción exterioridad/interioridad. Mas de ello nos ocuparemos más tarde.

Si no es concebible interioridad alguna que no esté restringida o limitada por lo externo, es preciso preguntarse: ¿en qué consiste la pasividad del recuerdo, es decir, aquello que en el mismo limita el hacer de la inteligencia? Del recuerdo hemos dado una caracterización meramente negativa: él no es otra cosa que la presencia de los contenidos de la intuición fuera del contexto de la espacio-temporalidad. El cambio con respecto a la intuición, como ya sabemos, no atañe al contenido intuído, con lo cual es el contenido (por tener su origen en la intuición) lo que limita o restringe el hacer de la inteligencia. Es el hecho de que el recuerdo deba forzosamente referirse a algo efectivamente intuído lo que constituye su pasividad. De lo que se deduce: mientras el contenido, la res a la que remite el representar, sea de naturaleza intuitiva, es decir, sea algo "dado», pasivamente captado, o como dice Hegel, algo «hallado», el hacer de la inteligencia estará esencialmente obstaculizado. Esta conclusión debe ser puesta en relación con lo más arriba indicado acerca de la tensión inherente a la noción de representación: que el representar esté esencialmente referido a la res, y que la res en cuestión, como acabamos de mostrar, sea un contenido proveniente de la intuición, comporta que aquello a lo que apunta la noción del representar no se cumpla de modo efectivo en la misma. Como ya sabemos, lo que hemos llamado cumplimiento efectivo del concepto del conocer se basa en un encadenamiento de momentos (en el que, por tanto, ningún momento puede «faltar»). Del recuerdo pues, entendido como la forma más elemental del representar, deberemos pasar a otras formas o momentos más cercanos a la realización del conocer. En dichas formas, y de acuerdo con la idea del conocer como "afirmación», lo que la inteligencia aporta frente a la pasividad de la intuición es algo más que una mera negación del contexto espacio-temporal. El que el contenido de la intuición, al ser recordado, pase a alojarse en un ámbito «interior», es decir, un ámbito en el que la inteligencia es activa, conlleva que la inteligencia pueda organizar y combinar dichos contenidos como le plazca, es decir, según relaciones "propias», no provenientes del ámbito de la «intuición» (en el que, propiamente hablando, no hay relaciones). Esto es lo que se conoce como «imaginación», y en ella es fácil reconocer un 
grado de actividad mayor que en la mera retención de contenidos intuitivos en que consiste el recuerdo ${ }^{30}$.

Acabamos de mencionar, a propósito de la imaginación, las relaciones «propias» de la inteligencia, no provenientes por tanto del contexto de la intuición. Si el modo propio en que se presentan los contenidos en la intuición es el «uno-fuera-de-otro", que la inteligencia organice y combine en la imaginación dichos contenidos (inicialmente desligados entre sí) según relaciones propias significa que ella los refiere los unos a los otros o los conecta, es decir, que ella opera con ellos aquello en lo que (según lo que más arriba dijimos de la asunción consecuente de la noción de repraesentatio) consiste precisamente la referencia válida a la res. Lo que según Hegel lleva a cabo propiamente la imaginación es «una subsunción de las representaciones singulares bajo una representación universal que constituye su conexión ${ }^{31}$, es decir, lo que con lenguaje kantiano podríamos llamar «síntesis». No es casual que Hegel emplee terminología kantiana precisamente en este punto. Síntesis es en Kant la operación propia del concepto, el cual, como hemos señalado más arriba, constituye para Kant un tipo o clase de representación. Por otro lado, hemos dicho que el «ir más allá» de la representación que se propone Hegel pasa por dejar de entender el concepto — tal como lo hace Kant- desde el punto de vista de la representación y de la estructura que le es propia. De lo que se sigue que la comprensión kantiana del concepto deberá, en la nueva concepción hegeliana, ser adecuada para describir la representación e inadecuada para describir el concepto en cuanto tal, y de ahí que Hegel se sirva en este contexto de terminología kantiana. Respecto a los productos del representar (y esto vale sobre todo para los productos de la imaginación), Hegel se refiere a ellos diciendo que son «aún» síntesis, indicando con este «aún» que el contenido del representar sigue siendo algo "hallado» o «dado», es decir algo que figura en el representar como algo que él mismo no ha producido, por tanto algo que limita o restringe la «realización»o «afirmación» del $\operatorname{conocer}^{32}$. El empleo del adverbio

${ }^{30}$ Enz. $\$ \$$ 455-456: «Die Intelligenz ist die Macht über den Vorrat der ihr angehörigen Bilder und Vorstellungen und so freies Verknüpfen und Subsumieren dieses Vorrats unter den ihr eigentümlichen Inhalt.»

${ }^{31}$ Enz., $\$ 457$.

32 Enz. \$451: «Aber indem das Vorstellen von der Anschauung und deren gefundenem Stoff anfängt, so ist diese Tätigkeit mit dieser Differenz noch behaftet, und ihre konkreten Produktionen in ihr sind noch Synthesen, die erst im Denken zu der konkreten Immanenz des Begriffes werden.» 
«aún» alude precisamente a este resto de pasividad que hace que, mientras haya síntesis, no podamos hablar todavía de un cumplimiento efectivo de aquello a lo que apunta la noción de repraesentatio.

Según lo antedicho, lo que obstaculiza el cumplimiento efectivo de la noción del conocer (concebido como «afirmación») es la naturaleza "hallada», «encontrada», de sus contenidos. Ahora podemos entrever que el único modo de eliminar este resto de pasividad consiste en que los contenidos a conectar por la inteligencia sean de la misma naturaleza que las relaciones mismas que operan dicha conexión. Dicho de otra manera: para que lo «hallado» de la representación sea efectivamente eliminado, lo que hasta ahora ha operado como conexión entre los diversos contenidos (las relaciones «propias» de la inteligencia) debe pasar él mismo a ser "contenido». Con arreglo a la noción que nos ha servido de guía hasta aquí, i. e. la de referencia, esto significa lo siguiente: el remitir a otra cosa en que consiste la repraesentatio debe ser ahora un remitir fundamentalmente a la inteligencia misma, a sus contenidos propios, esto es, a las relaciones que hasta ahora han efectuado la síntesis. Ahora bien, respecto a las combinaciones que efectúa la imaginación Hegel habla de «la materia, en la que el haber subjetivo se da una existencia representativa», refiriéndose con ello precisamente a los contenidos de la intuición, en virtud de los cuales el representar (en las modalidades consideradas hasta ahora) remite a algo existente. Puesto que intuir es percibir lo que existe, puesto que la noticia de lo existente no nos llega por otra vía que la intuición, el representar no puede prescindir de la intuición sin convertirse en algo inconsistente, sin correlato óntico alguno, como un recuerdo que no remite a nada efectivamente vivido o una imaginación sin referencia alguna a lo «real». Todo parece pues indicar que la intuición no puede dejar de ser el material del representar, con lo cual el hacer de la inteligencia no puede librarse de aquello que lo condiciona y lo limita. Salvo que la inteligencia sea capaz por sí misma de proporcionarse intuiciones, opción explícitamente rechazada por Kant en sus reflexiones en torno al intellectus archetypus ${ }^{33}$. Mas la imposibilidad de proporcionarse intuiciones, de producirlas espontáneamente, concierne únicamente a la interpretación de las mismas como el contenido al que el representar remite. Hay en efecto otro modo de concebir la intuición, a saber como «vehículo» o «medio» de un contenido que en sí mismo no es intuición; bajo esa

\footnotetext{
${ }^{33}$ Kant, Kritik der Urteilskraft, B 350.
} 
perspectiva la inteligencia es perfectamente capaz de producir por sí misma intuiciones, mediante las cuales ella aporta a sus productos propios - los pensamientos o las conexiones de las intuiciones entre sí- una «marca externa». Esto es justamente lo que tiene lugar en los productos simbólicos de la imaginación: un símbolo no es otra cosa que una configuración de naturaleza intuitiva, elaborada por la inteligencia, que remite a un contenido no-intuitivo, por tanto de naturaleza intelectual. Lo no-intuitivo hasta ahora eran las relaciones de la inteligencia en virtud de las cuales los contenidos intuitivos diversos eran referidos los unos a los otros; en un símbolo dichas relaciones pasan a ser el contenido mismo, re-presentado ahora ante la percepción mediante una configuración intuitiva - la parte visible, captable, del símbolo — espontáneamente producida por la inteligencia. De lo que se sigue que la inteligencia, cuando se representa un símbolo, propiamente se intuye a sí misma ${ }^{34}$.

Mas con ello no se ha eliminado aún del todo el resto de pasividad que condiciona el cumplimiento efectivo del concepto del conocer. Consideremos un símbolo concreto, por ejemplo el águila como símbolo de la fortaleza de Júpiter. Observemos que entre la imagen escogida por la inteligencia para representar el contenido y el contenido mismo hay cierta semejanza, de modo que la opción por dicha imagen no es «casual». El parentesco o la correspondencia del símbolo con lo simbolizado limita la libertad de la inteligencia de elegir imágenes para representar sus contenidos. El hecho mismo de que la inteligencia tenga que «optar» entre imágenes dadas, ya existentes, hace que ésta esté aún condicionada por lo "hallado» y que sólo se pueda hablar parcialmente de una producción espontánea de intuiciones. El único modo de eliminar este resto de pasividad consiste en que lo simbolizado y lo simbolizante no estén unidos por ningún tipo de ligazón. Esto significa: en la imagen que representa no debe poder hallarse nada que remita al contenido representado, de modo que la ligazón entre ambos dependa exclusivamente de un decreto arbitrario de la inteligencia. Pero entonces no estamos ya propiamente ante un símbolo, sino ante un signo. Un signo no es otra cosa que una configuración intuitiva, espontáneamente producida por la inteligencia, referida a un contenido intelectual —i. e. las relaciones o conexiones propias de la inteligencia de las que antes hablába-

${ }^{34}$ Enz. $\$ 457$ : «Die Intelligenz ist in der Phantasie zur Selbstanschauung in ihr insoweit vollendet, als ihr aus ihr selbst genommener Gehalt bildliche Existenz hat.» 
mos- con el cual no está unido por ningún tipo de vínculo natural. Esta formulación es incluso demasiado prolija, pues la ausencia de vínculo natural entre el signo y su significado y el carácter espontáneo de la producción de signos son en realidad dos maneras de decir lo mismo. En el signo la intuición deja definitivamente de tomar parte en el contenido - i. e. deja de valer por sí mismay asume el papel de mero «soporte» o "vehículo» del mismo. Más arriba hemos dicho que intuir es percibir lo que existe, de manera que sin referencia a la intuición el representar se vuelve algo inconsistente. Observemos ahora el notable giro que introduce en la cuestión la consideración del signo. El signo, por cuanto hace corresponder a los contenidos intelectuales una «marca intuitiva externa», dota a los mismos de la existencia que precisa el representar para no ser algo inconsistente. Mas al no tener dicha existencia otra función que la de soporte externo, es decir, al estar totalmente desposeída de autonomía, la inteligencia logra con ella el correlato óntico que precisa sin estar pasivamente condicionada por la misma. Estamos pues aparentemente ante la liberación definitiva de la inteligencia con respecto a lo «externo» o «hallado» (pasivamente captado), por tanto ante la eliminación de todo lo que hasta ahora obstaculizaba su realización. Es preciso recordar que con el paso de la intuición al recuerdo surge la contraposición entre el afuera, ámbito de los contenidos intuitivos, y el adentro, ámbito de actividad libre de la inteligencia. Con la reducción de la intuición a mero «soporte externo» de contenidos intelectuales el afuera deja de limitar la «interioridad» de la inteligencia, la cual pasa de este modo a constituirse en su propio afuera. Esta afirmación se comprende mejor si consideramos el signo in concreto, es decir, formando parte de un sistema de signos o lenguaje: el lenguaje entendido como sistema de signos posee una «objetividad» independiente de toda interioridad representativa, la cual se comporta respecto al mismo como ante algo «hallado», «encontrado». Pero, a diferencia de las modalidades anteriores del representar, lo «hallado» aquí por la inteligencia son —en virtud de su capacidad de significar, es decir, de referir intuiciones a pensamientos- sus propios contenidos.

En la sección 3 establecimos que es desde el supuesto de la representatividad que la cuestión rectora de los tiempos modernos - i. e. la pregunta acerca de la posibilidad del conocer- adquiere sentido. Pero el supuesto de la representatividad introducía a su vez otra cosa, a saber, la noción de autorreferencia, entendida como aquello en virtud de lo cual se da efectivamente referencia válida a la res, y el cumplimiento efectivo del concepto del conocer basado en dicha 
noción exigía dejar de abordar la cuestión moderna del conocer desde el punto de vista de su mera posibilidad, es decir, asumiendo que el conocer bien podría «no darse». ¿Qué aporta a este estado de cosas el signo como producto del representar? Al constituirse la inteligencia, en virtud del signo, en su propio afuera, la tensión inherente al concepto del representar entre referencia a la res y referencia al sujeto parece eliminarse: aquello a lo que remite la cara intuitiva del signo (el signans) es un pensamiento, una conexión entre intuiciones, por tanto algo "propio" de la inteligencia, de manera que el referir y el autorreferir coinciden. La «apropiación» en la que consiste el conocer (concebido desde la noción de autorreferencia) parece de este modo alcanzar su cumplimiento: no cabe ya hablar de algo «ajeno» al representante, pues la "cosa ajena» es, en tanto que signo, algo producido por $-\mathrm{y}$ por tanto perteneciente a- el representar. Evidentemente, Hegel no es el primero en haber visto que el signans remite a pensamientos, ni tampoco en haber observado que a través del signo la inteligencia se da una existencia externa, pero sí es el primero en haber convertido la tensión inherente a la noción de repraesentatio en objeto de consideración y en haber puesto en relación la misma con la naturaleza sígnica de la inteligencia. En este punto es preciso recalcar lo siguiente. Acabamos de decir que con el surgimiento del signo la tensión inherente al representar entre la referencia a la res y la autorreferencia "parece eliminarse», es decir, que no se elimina de modo efectivo. Lo que con ello más bien se ha logrado es reordenar los términos de la problemática de tal modo que la vía exacta de su solución se haga visible. Como bien sabemos, el supuesto de la representatividad fuerza a formular la pregunta rectora de los tiempos modernos - i. e. la pregunta por el conocer- en términos de posibilidad. Al pasar a ser la res del representar el pensamiento mismo no parece ya tener sentido concebir su referencia como algo que pueda «no darse», pues la res no es ya más algo «ajeno» a la inteligencia. Sin embargo, hemos señalado más arriba que el lenguaje entendido como sistema de signos posee una objetividad independiente de toda interioridad representativa, la cual se comporta respecto al mismo como ante algo «hallado», «encontrado». Hay pues efectivamente algo "ajeno" al conocer, pero eso ajeno es justamente representación, es decir, productos discursivos ya existentes, sedimentados históricamente. Si el conocer es esencialmente apropiación, entonces aquello a apropiar ahora son representaciones, no ya concebidas como contenidos provenientes de la intuición (Kant), sino como pensamientos sígnicamente articulados, es decir, como discursos. A partir de ahí adquieren sentido muchos filosofemas hegelianos, como por ejemplo, la captación de la filosofía como una actividad que siem- 
pre llega tarde (pues el representar la precede siempre) ${ }^{35}$, o la idea de que los productos del espíritu forman una substancia de la que, a modo de naturaleza inorgánica de la subjetividad, el pensar se tiene que apropiar ${ }^{36}$. La pregunta que se plantea entonces ahora es la siguiente: puesto que el conocer es apropiación, ¿en qué consiste exactamente la apropiación de la res concebida como signo? Su esclarecimiento nos tiene que dar la clave de lo que hemos llamado «ir más allá de la representación».

\section{La repraesentatio como signo y la tarea del pensar}

Al principio de la Enciclopedia Hegel afirma que «la filosofía carece de la ventaja, que favorece a otras ciencias, de poder suponer sus objetos como inmediatamente ofrecidos por la representación ${ }^{37}$. Lo que distingue la filosofía (definida más adelante como "consideración pensante de los objetos») del resto de saberes es que éstos, en tanto que saberes particulares, están siempre circunscritos a un campo determinado de objetos. Dicha circunscripción o limitación temática es lo que Hegel expresa en el pasaje citado como «suponer sus objetos»: un saber particular se ciñe a un campo determinado de objetos en la medida en que lo supone como dado. Mas de la suposición del objeto no se deriva únicamente la particularidad del saber referido a él, sino también la pluralidad contingente misma de los saberes particulares. Los saberes referidos a un objeto determinado forman un agregado contingente precisamente porque la suposición de su objeto les hace ser «particulares» $\mathrm{o}$ «finitos», y en cuanto tales sólo pueden formar conjuntamente una mera pluralidad aditiva o contingente. Observemos además que la suposición del objeto de un saber particular viene dada en el pasaje citado por la dependencia respecto a la representación. Lo cual concuerda perfectamente con la caracterización que hemos dado repetidas veces de la representación como «apropiación inconclusa», es decir, condicionada por lo "hallado». Estamos pues ante la manifestación triple de una misma problemática: suposición de objeto, particularidad del saber (con la consecuente pluralidad contingente de saberes), dependencia de la representación. De lo que se deduce que el buscado cumplimiento efectivo del concepto del conocer deberá presentar los siguientes rasgos:

\footnotetext{
${ }^{35}$ Grundlinien der Philosophie des Rechts, Prefacio XXIV.

${ }^{36}$ Phänomenologie des Geistes, 25-26.

${ }^{37}$ Enz. $\$ 1$.
} 
no-suposición de objeto, saber no-particular (por tanto absoluto), saber no-representativo.

Concentrémonos en el último rasgo. Para saber en qué consiste un saber norepresentativo hemos de dirigir nuestra atención a la estructura de lo que ha resultado ser la expresión más perfecta y acabada del representar, es decir, el signo. El signo, como sabemos, consiste en una configuración intuitiva (signans) referida a un contenido intelectual (signatum). El hecho de que la res a la que remite el signans no sea otra cosa que pensamientos nos ha aparecido ya antes en cierto modo como la supresión de lo "hallado", mas dicha supresión se ha mostrado inmediatamente como aparente, por cuanto el signo considerado in concreto forma parte de un sistema independiente de toda interioridad representativa, por tanto de algo "hallado», «encontrado». Si ahora consideramos el signo en su pura estructura elemental, observaremos de nuevo que la contraposición fuera-dentro, que antes establecimos como índice de un conocer condicionado por lo «hallado», todavía se mantiene. En efecto, que en el signo se establezca una correspondencia entre una configuración intuitiva (i. e. algo «externo») y un pensamiento (i. e. algo «interior») no elimina la distinción fundamental entre ambos ámbitos; es más, la hace intercambiable, pues el ámbito de aquello a lo que remite el signans (i. e. de los significados) puede ser igualmente considerado como «externo» al mismo, siendo entonces la significación una suerte de «traducción» entre órdenes diversos, externos los unos a los otros. Si la distinción fuera-dentro se mantiene es porque signans y signatum son, en virtud del arbitrio que los une, externos el uno al otro. Es por tanto en la estructura remisiva misma del representar que se origina la distinción fuera-dentro; es por tanto en ella en la que consiste en última instancia la suposición de objeto (con la consecuente particularidad de los saberes). De ahí se desprende una conclusión cuya significación concreta está aún por determinar: el saber no-representativo, aquél justamente en que el concepto del conocer se realiza de modo efectivo, deberá ser un saber tal que en él se elimine la distinción signans-signatum. Las declaraciones mismas de Hegel a propósito del pensar en su relación con el representar confirman esta conclusión: «La memoria es de esta manera el paso a la actividad del pensamiento que ya no tiene significación, esto es, lo subjetivo ya no es algo distinto de su objetividad, (...)»38. La supresión de la distinción entre referencia váli-

\footnotetext{
${ }^{38}$ Enz. $\$ 464$.
} 
da a la res (objetividad) y autorreferencia (subjetividad) es concebida aquí como equivalente de la supresión de la significación en cuanto tal, es decir del mero remitir de un signans a un signatum ${ }^{39}$. Podemos llegar a la misma conclusión por otra vía. Si el representar consiste fundamentalmente, tal como indicamos al principio de nuestra exposición, en un suplantar o ponerse en lugar de la cosa (ausente), ¿̇tiene sentido hablar de semejante suplantación allí donde no hay suposición alguna de objeto? Dicho aún de otra manera: en un saber concebido como no-particular, es decir, no referido a objeto determinado alguno, ¿acaso no constituye el desdoblamiento repraesentatio/repraesentatum una superfluidad injustificada? Si el conocer entendido como realización efectiva no admite un cumplimiento meramente posible (es decir, cuyo contrario es pensable) de su concepto, es decir, no puede estar referido a una res externa, ya que en ese caso su realización efectiva quedaría relegada al ámbito de lo posible, entonces la articulación discursiva del mismo no puede consistir en nombres unidos de modo externo a sus significados correspondientes, pues eso introduciría la contingencia de nuevo. Debemos pues concluir que, en el saber buscado, las palabras no difieren ya de las $\operatorname{cosas}^{40}$.

${ }^{39}$ Es importante no confundir lo que se aquí se está describiendo con una suerte de saber «intuitivo» (propio de un intelecto arquetípico o Dios), opuesto a un saber «discursivo» o, como dice Leibniz, «supositivo» (propio de las criaturas). La distinción entre ambos atraviesa toda la edad moderna, de tal manera que en los pensadores anteriores a Hegel la pregunta por el conocer se aborda - implícita o explícitamente- tomando como punto de referencia aquel saber «que no poseemos», i. e. un saber no-discursivo. Hegel no elimina el saber discursivo o supositivo en favor de su opuesto, sino la distinción entre ambos; si hubiera que privilegiar un término ese sería justamente la discursividad, pues lo que ha mostrado nuestra exposición es que ella, en tanto que formada por productos ya existentes, «hallados», constituye el verdadero correlato existencial del conocer concebido como apropiación.

${ }^{40}$ Se puede (y se debe) poner esto en relación con los excelentes análisis de F. M. Marzoa acerca de la noción leibniziana de characteristica universalis, según la cual un sistema de signos (characteristica) no referido a ningún campo particular de objetos, es decir, válido para tratar cualquier tipo de cuestión (universalis), no presentaría ya diferencia con las cosas mismas. La diferencia con respecto al planteamiento que estamos describiendo aquí está indicada ya en la nota precedente: la idea leibniziana de un saber en el que las palabras no difieren de las cosas mismas se basa justamente en la contraposición mencionada entre el saber propio de un intelecto arquetípico y el saber "supositivo» o «discursivo" propio de las criaturas, y de ahí que la characteristica universalis constituya un saber que no poseemos. Hegel, por el contrario, elimina la contraposición entre ambos saberes haciendo de la discursividad la realidad efectiva en cuanto tal y quitándole así el carácter de saber condicionado, finito (pues hasta Hegel discursividad es sinónimo de finitud), «supositivo", opuesto al saber intuitivo reservado a Dios; así se explica también la disolución de la contraposición en Hegel entre mediación e inmediatez. 
Conectemos este último resultado con las reflexiones con las que cerramos el apartado anterior. Allí se estableció que lo «hallado» por la inteligencia lo forman ahora los productos discursivos, sígnicamente articulados, ya existentes. Al saber no-representativo (o, lo que es lo mismo, al pensar) le deben preceder siempre dichos productos, los cuales, en virtud justamente de esta precedencia temporal (pues no han sido todavía «apropiados»), presentan los rasgos de la suposición de objeto y de la pluralidad contingente. La tarea del pensar respecto a estos productos «hallados» es ponerlos como propios, es decir, destruir los supuestos en que se basan —y de los que se deriva su «particularidad»— y de este modo eliminar su dispersión contingente, es decir, establecer su continuidad. El modo exacto en que esto se lleva a cabo es justamente mediante la eliminación de la significación o estructura remisiva del representar en cuanto tal. Si la significación consiste en que a un signans le corresponda un signatum determinado (con exclusión de otro), la eliminación de la misma no puede ser otra cosa que la destrucción de esta correspondencia, es decir: hacer que los nombres dejen de "tener» los significados que, en el estado de «hallados» o "previamente existentes», les están asignados. En esto consiste propiamente lo que Hegel llama «dialéctica» o «fluidificación de los pensamientos», y de ningún otro modo es concebible la articulación discursiva de un saber no condicionado por lo «hallado». En efecto, el tránsito ininterrumpido de las determinaciones conceptuales, en que se basa el proceder hegeliano, no se explica satisfactoriamente más que mediante la destrucción sistemática de la ligazón que une los significantes con sus significados, y es de este modo que una determinación «dada» puede transitar a su opuesta. Puesto que en dicha ligazón fija se basa la «estabilidad» de los contenidos que forman los saberes particulares, su eliminación comporta eso que Hegel llama «movimiento del concepto», en el que se fundamenta la consistencia y la validez de su edificio teórico ${ }^{41}$.

\section{Bibliografía}

CASSIRER, E. (1910). Substanzbegriff und Funtkionsbegriff, Berlin.

Chauvin, S. (1967). Lexicon philosophicum, 1713, Düsseldorf 1967.

${ }^{41}$ De ello nos ocupamos con más detalle en nuestra tesis doctoral, intitulada Zeichen und Subjekt im logischen Diskurs Hegels y pendiente aún de publicación. 
Clark, M. (1971). Logic and System. A Study of the Transition from "Vorstellung» to Thought in the Philosophy of Hegel, The Hague.

CoOK, D. J. (1973). Language in the Philosophy of Hegel, The Hague/Paris.

Descartes, R. (1897-1913). Oeuvres de Descartes, hrsg. v. Ch. Adam u. P. Tannery, Paris.

Fulda, H. F. (1978). Hegels Dialektik als Begriffsewegung und Darstellungsweise, in: R. P. Horstmann (Hrsg.): Seminar: Dialektik in der Philosophie Hegels, Frankfurt a. M., 124-174.

- (1978).Unzulängliche Bemerkungen zur Dialektik, in: R. P. Horstmann (Hrsg.): Seminar: Dialektik in der Philosophie Hegels, Frankfurt a. Main, 109-127.

- (2001). Das endliche Subjekt der eigentlichen Metaphysik, in: J. Stolzenberg (Hrsg.): Subjekt und Metaphysik. Konrad Cramer zu Ehren aus Anlaß seines 65. Geburtstags, Göttingen, 77-78.

GoCleniUs, R. (1964). Lexicon philosophicum, quo tantam clave philosophiae fores aperiuntur, 1613, Hildesheim.

GuÉroult, M. (1953). Descartes selon l'ordre des raisons, 2 vol., Paris.

HeGEL, G. W. F. (1968 ff.). Gesammelte Werke, in Verbindung mit der Deutschen Forschungsgemeinschaft hrsg. v. der Rheinisch-Westfälischen Akademie der Wissenschaften, Hamburg.

- (1998). Grundlinien der Philosophie des Rechts, mit Hegels eigenhändigen Randbemerkungen in seinem Handexemplar, hrsg. v. Johannes Hoffmeister, Hamburg.

- (1988). Phänomenologie des Geistes, hrsg. v. Hans-Friedrich Wessels u. Heinrich Clairmont, m. Einl. v. Wolfgang Bonsiepen, Hamburg.

Heidegger, M. (1976 ff). Gesamtausgabe, Frankfurt a. Main.

Janke. W. (1963). Leibniz. Die Emendation der Metaphysik. Frankfurt a. Main.

KANT, I. (1902 ff). Gesammelte Schriften, Bde. I -XXII hrsg. v. der Königlich Preußischen Akademie der Wissenschaften, Berlin 1902 ff.; Bd. XXIII hrsg. v. der Deutschen Akademie der Wissenschaften, Berlin 1956; ab Bd. XXIV hrsg. v. der Akademie der Wissenschaften in Göttingen, Berlin 1966 ff.

LEIBNIZ, G. W. (1960-1961). Die philosophischen Schriften von Leibniz, hrsg. v. C. I. Gerhardt, Berlin 1875-1890, Neudruck: Hildesheim 1960-1961.

(1990). Les notions philosophiques. Dictionnaire. Dirigé par Sylvain Auroux. Paris.

Malebranche, N. (1979). Euvres, ed. de G. Rodis-Lewis. 
MARION, J. L. (1975). Sur l'ontologie grise de Descartes. Savoir aristotélicien et science cartésienne dans les Regulae, Paris.

- (1981). Sur la théologie blanche de Descartes, Paris.

MarTínez MarzoA, F. (1991). Cálculo y ser (Aproximación a Leibniz), Madrid.

- (1992). De Kant a Hölderlin, Madrid.

- (2009). Pasión tranquila. Ensayo sobre la filosofía de Hume, Madrid.

MiCRAeLIUS, J. (1966). Lexicon philosophicum terminorum philosophis usitatorum, 1653, Düsseldorf 1966.

(1982). Oxford Latin Dictionary, Oxford University Press, New York.

Perler, D. (1997). Descartes, critique de la théorie médiévale des species, 151-153, en: Descartes et le moyen âge, ed. p. Joël Biard et Roshdi Rashed, Paris.

Saussure, F. De (1982). Cours de linguistique générale (1916), ed. Tullio de Mauro, Paris 1982.

SpINOZA, B. (1986 ff.). Sämtliche Werke, hrsg. u. m. Einl., Anm. u. Reg. versehen v. Carl Gebhardt, Hamburg.

- (2004): Vocabulaire européen des philosophies, dirigé par B. Cassin, Seuil.

Recibido: $11 / 11 / 2010$

Aceptado: 3/05/2011 